\title{
VANTAGENS DO RASTREAMENTO PRECOCE DE METÁSTASES POR TOMOGRAFIA COMPUTADORIZADA NA ROTINA CLÍNICA ONCOLÓGICA DE TUMORES MAMÁRIOS EM CADELAS: revisão de literatura
}

\author{
Advantages of early metastasis screening by computed \\ tomography in the clinical oncology routine of breast \\ tumors in bitches: literature review
}

Beatriz Canarin de Oliveira ${ }^{1 *} \mathbb{D}_{\text {; }}$ Gislaine da Silva Rosso ${ }^{1}$; Mateus Dagostim Sartor ${ }^{1}$; Flávia Coelho de Souza²; Ewerton Cardoso ${ }^{3}$

*Autor Correspondente: Beatriz Canarin de Oliveira, Rua Pedro Rodrigues Lopes, 15, Comerciário, Criciúma, SC, Brasil. CEP 88802-465.

E-mail: biacanarin@hotmail.com

Como citar: OLIVEIRA, B. C. de et al. Vantagens do rastreamento precoce de metástases por tomografia computadorizada na rotina clínica oncológica de tumores mamários em cadelas: revisão de literatura. Revista de Educação Continuada em Medicina Veterinária e Zootecnia do CRMV-SP, São Paulo, v. 19, n. 1, 2021, e38089. DOl: https://doi.org/10.36440/recmvz.v19i1.38089.

Cite as: OLIVEIRA, B. C. de et al. Advantages of early metastasis screening by computed tomography in the clinical oncology routine of breast tumors in bitches: literature review. Journal of Continuing Education in Veterinary Medicine and Animal Science of CRMV-SP, São Paulo, v. 19, n. 1, 2021, e38089. DOI: https://doi. org/10.36440/recmvz.v19i1.38089.

\section{Resumo}

Os avanços clínicos, terapêuticos e diagnósticos ocorridos na Medicina Veterinária permitiram que a longevidade dos animais de estimação fosse ampliada. Com isso a casuística de atendimentos oncológicos na rotina clínica veterinária também vem crescendo, visto que a idade avançada é um grande fator predisponente ao câncer. 0 diagnóstico precoce é fundamental para o sucesso terapêutico, e os exames de imagem apresentam grande utilidade para a detecção tumoral e de metástases. 0 presente trabalho é uma revisão bibliográfica que analisa as vantagens da aplicabilidade de exames por imagem, mais precisamente da tomografia computadorizada (TC), em casos oncológicos de tumores das glândulas mamárias, com destaque para a sua importância no diagnóstico, estadiamento,

\footnotetext{
1 Discente de Medicina Veterinária, Centro Universitário Barriga Verde, Orleans, SC, Brasil

2 Diretora de Pesquisa, Hospital Veterinário Florianópolis, Florianópolis, SC, Brasil

3 Professor de Técnica e Clínica Cirúrgica, Centro Universitário Barriga Verde, Orleans, SC, Brasil
} 
planejamento e acompanhamento terapêutico na rotina clínica oncológica veterinária.

Palavras-chave: Cães. Gatos. Neoplasia. Oncologia. Tomografia Computadorizada.

\section{Abstract}

With the increase in the longevity of pets, mainly dogs and cats, due to their closer relationship with humans and also the clinical, therapeutic and diagnostic advances that occurred in veterinary medicine, it was observed an increase in the occurrence of oncological cases in the routine attendance of small animals. This article perform a bibliographic review, analysing the advantages of the applicability of imaging exams, more precisely computed tomography (CT), in oncological cases of tumor of the mammary glands, aiming to demonstrate its importance in the diagnosis, staging and therapeutic planning in veterinary oncology clinical routine.

Keywords: Dogs. Cats. Neoplasia. Oncology. Computed Tomography.

\section{Introdução}

O número de animais de estimação, principalmente cães e gatos, tem aumentado cada vez mais no mundo todo. Esse aumento populacional tem como consequência um maior estreitamento da relação entre o homem e seus animais de companhia, determinando uma maior atenção e busca de cuidados veterinários, principalmente os relacionados às implicações clínicas do câncer, uma vez que animais mais idosos têm maior risco de desenvolver essa doença. Neste contexto, as possíveis etiologias do câncer vêm sendo cada vez mais estudadas e pesquisadas, considerando: idade, raça, alimentação, medicação e hormônios já administrados, além de outros fatores que possam estar predispondo ao desenvolvimento das diferentes neoplasias (MOREIRA et al., 2018).

A evolução de pesquisas e o desenvolvimento de novas terapêuticas destinadas a ampliar a qualidade e sobrevida dos pacientes, fez com que a oncologia ganhasse cada vez mais espaço dentro da rotina clínica de pequenos animais (JANSSENS et al., 2013). A complexidade do câncer nesses pacientes envolve fatores biológicos do animal, bem como fatores emocionais dos tutores, que devem ser levados em consideração pelo médico-veterinário, sempre buscando a individualização terapêutica do animal. De fato, o planejamento, desde a abordagem do paciente oncológico, é fundamental para a obtenção de resultados positivos no tratamento.

O diagnóstico precoce de neoplasias e de possíveis metástases é imprescindível para o sucesso terapêutico, bem como para um melhor prognóstico dos pacientes. Os exames de imagem têm sido de extrema importância na clínica oncológica, tanto no diagnóstico quanto no estadiamento e, inclusive, no planejamento terapêutico, seja ele cirúrgico, quimioterápico ou radioterápico (LORIGADOS et al., 2013), bem como no monitoramento da resposta neoplásica ao tratamento de escolha.

Os tumores mamários são os tumores mais comuns em cães do sexo feminino (CASSALI et al., 2014), constituindo em torno de $52 \%$ dos tumores que acometem as cadelas, onde $82 \%$ dessas neoplasias são malignas (FREHSE et al., 2014). No Brasil, a ocorrência de tumores mamários malignos em cadelas chega à 70\% e acomete, principalmente, fêmeas entre 7-12 anos (DE NARDI et al., 2017). O local mais comum de metástases em casos de tumores malignos das glândulas mamárias são os pulmões, contudo, dependendo da sintomatologia clínica individual do paciente, podem ser indicados outros testes diagnósticos adicionais em outros locais anatômicos (MEDEIROS, 2017).

O presente trabalho é uma revisão bibliográfica que analisa a utilidade do diagnóstico por imagem, principalmente da tomografia computadorizada (TC), aplicada a detecção tumoral e de lesões metastáticas, visando o planejamento terapêutico e estadiamento tumoral pelo método TNM (tumor, linfonodo e metástases), bem como a avaliação da resposta terapêutica com emprego do método RECIST (Response Evaluation Criteria in Solid Tumors) em casos de animais acometidos por tumores mamários. 
Também é discutida a importância crescente da tomografia computadorizada na Oncologia Veterinária para que seja proporcionada uma vida mais longa e com qualidade para pacientes portadores de câncer.

\section{Epidemiologia e etiologia do câncer em pequenos animais}

A ocorrência de neoplasias é cada vez mais frequente na rotina clínica veterinária, estando entre as principais afecções observadas em cães e gatos (CANOLA et al. apud DALECK; DE NARDI, 2017). Em cães, os dados epidemiológicos referem-se à incidência de aproximadamente um em cada três animais. Já em felinos a ocorrência é um pouco menor, um caso para quatro a cinco (LEANDRO; SÁ, 2016). A gravidade da manifestação do quadro clínico depende de fatores relacionados ao próprio paciente como condição física, questões imunológicas, estado nutricional, presença de doenças concomitantes e ainda a pré-genética (QUEIROGA; LOPES, 2002; OLIVEIRA FILHO et al., 2010).

A etiologia do câncer ainda não é totalmente conhecida, mas sabe-se que a ocorrência de mutações genéticas espontâneas ou induzidas por agentes externos patogênicos está intimamente ligada ao seu desenvolvimento. Hoje os fatores envolvidos no desenvolvimento dessas mutações são classificados como intrínsecos ou extrínsecos (MOREIRA et al., 2018).

Os fatores extrínsecos englobam metais, radiações e radicais livres de oxigênio, processos inflamatórios de longa ocorrência e até mesmo microrganismos como vírus e bactérias. Os fatores intrínsecos estão relacionados a questões do próprio paciente como idade, dieta, níveis hormonais e predisposição genética (CANOLA et al. apud DALECK; DE NARDI, 2017). A idade avançada está intimamente relacionada à ocorrência de câncer, pois quanto mais longa é a vida do animal, maior é a sua exposição aos fatores externos, que ampliam as chances de manifestação por problemas intrínsecos, ou ainda devido à somatória dos agentes ambientais aos fatores intrínsecos, que aumentam as chances de ocorrência de processos anormais de multiplicação celular (MORIMOTO et al., 2017).

\section{Diagnóstico Tumoral}

Os avanços registrados na Medicina Veterinária, principalmente na área oncológica e de diagnóstico por imagem, aliados a um maior laço afetivo estabelecido entre os tutores e seus animais de estimação têm determinado uma crescente conscientização acerca do câncer nos animais de companhia, que têm favorecido a detecção precoce de processos neoplásicos (MEDEIROS, 2017). Em animais idosos, a presença de outras doenças concomitantes dificulta o estabelecimento do diagnóstico das neoplasias.

A manifestação clínica do câncer nos animais, assim como no homem, não se restringe apenas à localização tumoral. Silva (2006) destaca que os mecanismos de estresse participam do desenvolvimento de síndromes paraneoplásicas. Além disso, animais portadores de neoplasia são mais suscetíveis à ocorrência de processos infecciosos, pois têm as suas proteções imunológicas comprometidas (MOREIRA et al., 2018).

As técnicas de imagem apresentam um papel fundamental tanto para o estabelecimento do diagnóstico inicial da doença quanto para a análise da resposta terapêutica dos casos de oncologia (BRELINGER, 2015). Os raios X descobertos por Wilhelm Conrad Röentgen, em 1895 (SERKOVA et al., 2009), trouxeram um recurso de grande importância para o processo de diagnóstico tanto na Medicina Humana quanto na Veterinária. De fato, as técnicas diagnósticas que utilizam os raios $X$ como base na formação de imagem têm sido aprimoradas devido à contínua produção de aparelhos com maior qualidade. Uma dessas principais evoluções foi o desenvolvimento da primeira máquina de tomografia computadorizada (TC) pelo matemático e físico Godfrey Hounsfield, no ano de 1972 (CARVALHO, 2007). 
A tomografia se baseia na formação da imagem de acordo com as diferentes densidades teciduais (WITHROW et al., 2013) e, diferentemente do raio x, ela capta imagens livres de sobreposição de estruturas adjacentes. A TC de tórax é útil para a identificação de nódulos primários e de metástases em mediastino, pleura e pulmão, que não são detectados pelos raios X (CANOLA et al. apud DALECK; DE NARDI, et al., 2017).

Os tumores de mama visíveis a olho nu fazem com que o tutor leve o animal ao médicoveterinário. 0 diagnóstico inicial, firmado com o emprego de exames de citologia e/ou histopatologia, que permitem a caracterização da diferenciação do tecido tumoral, deve ser somado aos exames de imagem que possibilitam a identificação de possíveis metástases.

\section{Estadiamento tumoral e identificação de metástases}

A análise da extensão, disseminação e malignidade do câncer, denominado de estadiamento, fornece informações sobre a taxa de crescimento da doença, órgão de origem e do seu grau de metastização (BATSCHINSKI; TEDARDI apud DALECK; DE NARDI, 2017). A formação de metástase oriunda de neoplasia mamária é classificada como: regional, quando afeta linfonodos regionais, ou à distância, quando ocorre a disseminação linfática ou sanguínea. A ordem de ocorrência decrescente dos processos metastáticos de neoplasias mamárias é representada por: pulmão, linfonodos cervicais superficiais, esternais ou inguinais profundos e/ou em tecido hepático, renal, ósseo, cardíaco ou pele (LANA et al., 2007).

Cerca de $25 \%$ a $50 \%$ das cadelas com tumores mamários malignos já apresentam metástases no momento do diagnóstico (FOSSUM, 2014), o que ressalta a importância do estabelecimento do diagnóstico preciso e precoce desses processos metastáticos e das suas respectivas terapias (HEDLUND apud FOSSUM, 2014). Contudo, quando há suspeita de metástase em outro local que não sejam os pulmões, podem ser indicados exames de imagem como ultrassonografia abdominal e radiografias esqueléticas (SORENMO et al., 2011).

Saber se existe a presença ou não de metástases, seja ela nos linfonodos da cadeia regional ou em qualquer outra região do corpo do paciente é extremamente importante para a classificação tumoral dentro dos sistemas de estadiamento, com a definição do tratamento e prognóstico do câncer de mama (PINHEIRO et al., 2014). Cassali et al. (2014) afirmam que os tumores mamários são estadiados de acordo com o sistema TNM da Organização Mundial de Saúde (OMS). A letra " $T^{\text {" }}$ está relacionada à extensão e característica do nódulo primário, o " $\mathrm{N}$ ", à presença de metástase em linfonodo regional e o " $M$ ", à metastização à distância. Existe ainda uma subclassificação em $T 1, T 2$, T3 e T4, N0 a N3, M0 e M1, baseados em tamanho tumoral, presença ou não e locais de ocorrência metastática (BATSCHINSKI; TEDARDI apud DALECK; DE NARDI, 2017). Portanto a identificação do estágio tumoral de um paciente com neoplasia mamária, assenta-se nas informações colhidas sobre o tamanho do tumor, o acometimento dos linfonodos e a presença de metástases. Também deve ser levado em consideração o maior diâmetro tumoral e, em casos de cães com mais de um tumor, devem ser utilizadas as informações relacionadas ao maior tumor maligno (SORENMO et al., 2011).

0 processo de estadiamento tumoral deve ser feito antes do estabelecimento do protocolo terapêutico, pois possibilita a avaliação da evolução tumoral, das possibilidades de progressão no seu sítio de origem e inclusive o desenvolvimento de metástases. Além disso, o estágio também possui função prognóstica, pois nos estágios mais avançados é esperada uma pior resposta terapêutica. Com isso, o completo estadiamento é fundamental para a escolha do procedimento terapêutico que será aplicado ao paciente (SORENMO et al., 2011).

Hellmen et al. (1993) ressaltam que a radiografia detecta nódulos pulmonares com seis a oito $\mathrm{mm}$ de diâmetro e ainda é o método de diagnóstico de imagem mais utilizado para avaliação de pacientes com suspeita de metastização pulmonar. Entretanto, LAMB (2010) afirma que os nódulos 
pulmonares com quatro a cinco mm de diâmetro já podem ser observados na radiografia pulmonar. Ressalta-se, contudo, que Canola et al. (apud DALECK; DE NARDI, 2017) destacam que resultado radiográfico negativo não exclui a possibilidade de metastização pulmonar, porém inferem que a TC apresenta uma eficiência diagnóstica de lesões pulmonares consideravelmente melhor, permitindo e identificando as metástases de forma mais precoce. Isso ocorre, pois o exame permite a identificação de nódulos com tamanho de um a três mm de diâmetro. Na Medicina Humana, a TC é o método padrão para a avaliação de pacientes oncológicos com metástases pulmonares.

Otoni et al. (2010) observaram que a TC apresenta maior sensibilidade que as radiografias torácicas para a detecção de metástases pulmonares e propõe que ela deva ser realizada em todos os pacientes com quadro de tumor mamário, pois o diagnóstico precoce e o tratamento da doença metastática têm um forte impacto na resposta terapêutica.

Schwarz e Tidwell (1999) argumentam que a radiografia convencional é o principal exame de imagem na análise torácica. No entanto, outros métodos de imagem, como a tomografia computadorizada, fornecem informações que não são detectadas na radiografia comum e são de grande importância para se chegar a um diagnóstico final. Apesar de sensível para diagnosticar nódulos pulmonares, a TC tem baixa capacidade de os caracterizar como metastáticos e, portanto, torna-se necessário o emprego de outros exames para que o diagnóstico diferencial possa ser estabelecido. Esses exames devem analisar o tecido do nódulo para ver se as células presentes no mesmo são compatíveis com as do tumor mamário (BURGENER; KORMANO apud FONSECA PINTO, 2007). Além disso, é praticamente impossível que a radiografia possa distinguir as várias etiologias da formação de nódulos pulmonares. Isso ocorre devido à similaridade tecidual na aparência dos tumores, granulomas e abcessos (LAMB, 2010).

Dias (2012) verificou que a radiografia torácica realizada para visualização pulmonar não apontou a presença de lesões nodulares no pulmão de um paciente (Figura 1). Contudo, quando foram feitas imagens pulmonares desse mesmo paciente, com o emprego da TC, foram observadas imagens compatíveis com nodulação pulmonar com cerca de 7,5mm (Figura 2).

Figura 1. Imagem radiográfica de tórax canino sem indícios nodulares
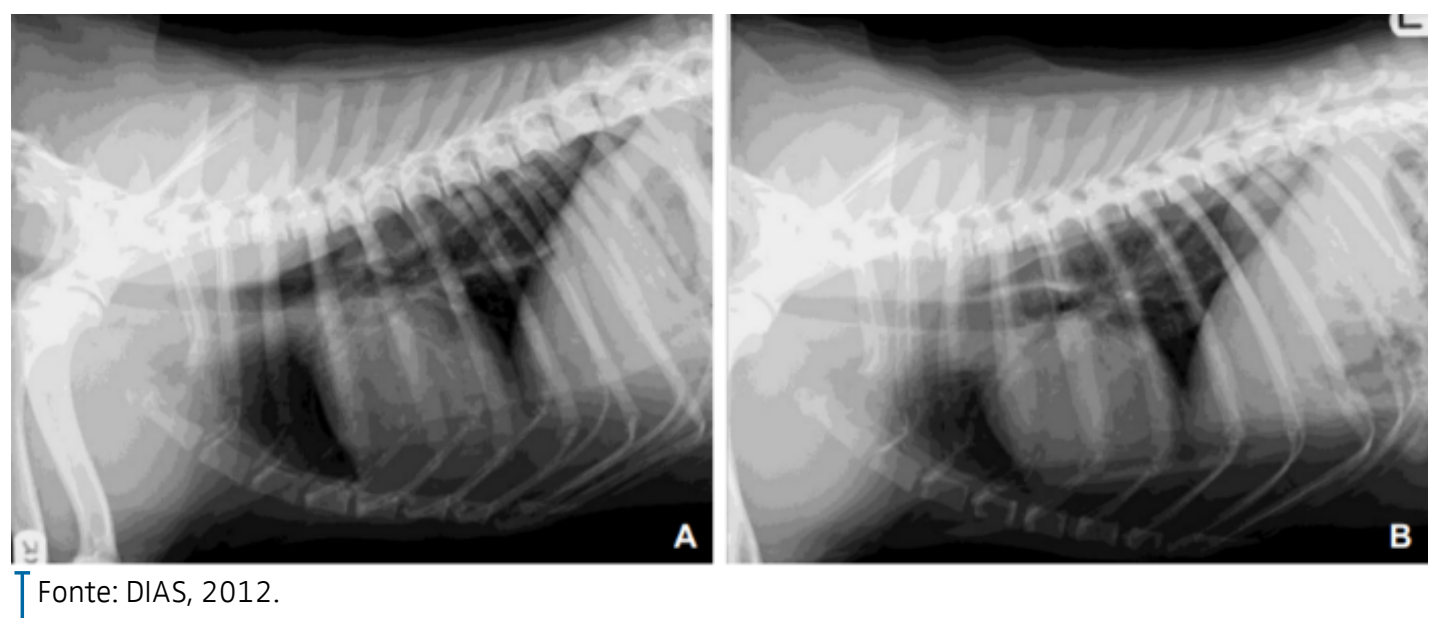

A) Radiografia na projeção latero-lateral direita. B) Radiografia na projeção latero-lateral esquerda. Em ambas as imagens não são vistas alterações com nódulos pulmonares. 
Figura 2. Imagem de TC pulmonar com presença nodulação pulmonar
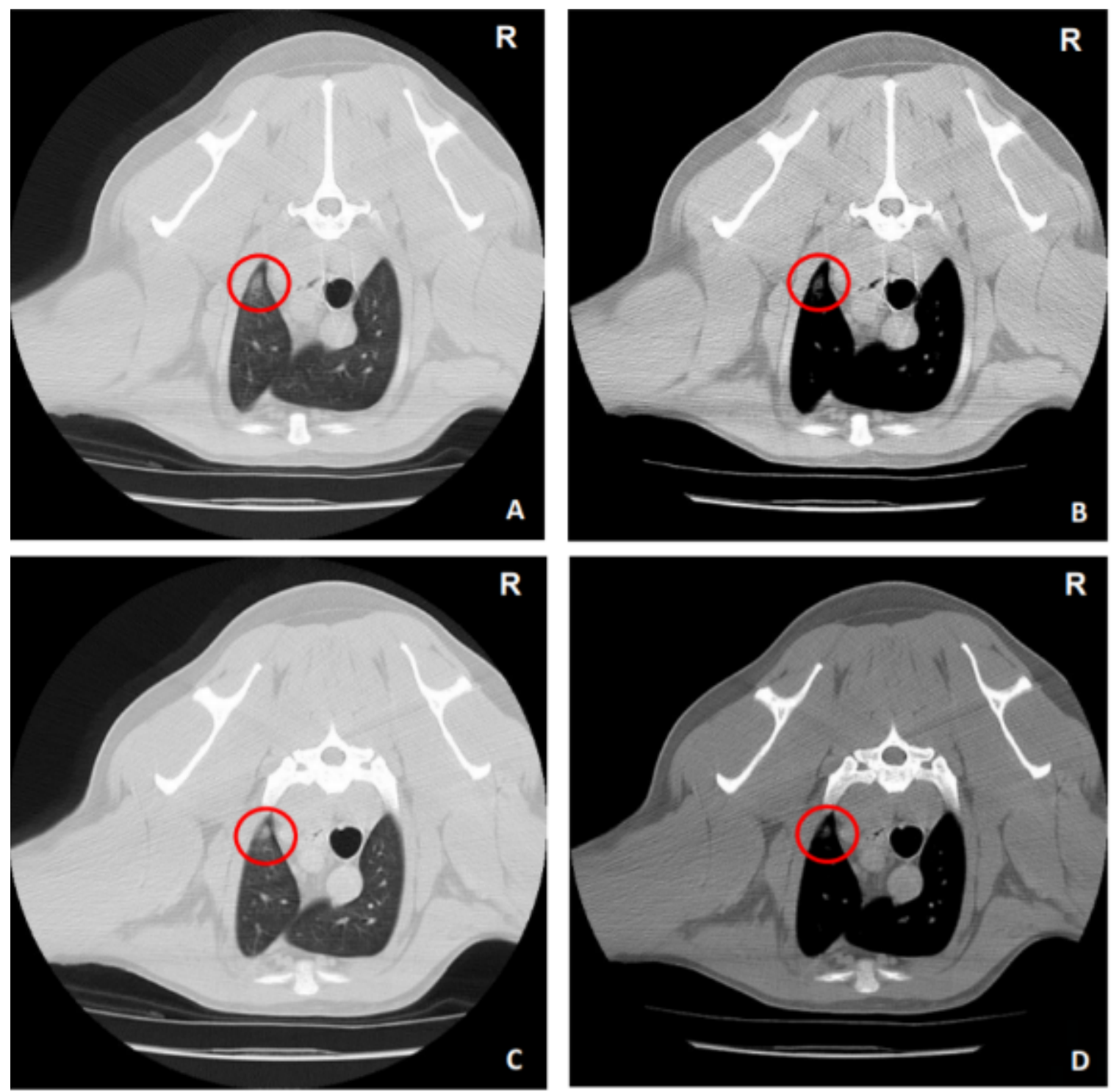

TFonte: DIAS, 2012.

A) Imagem de TC, em janela de pulmão, com indícios de lesão nodular de pequenas dimensões na periferia do lobo pulmonar cranial esquerdo. B) Imagem de TC do estudo simples, na janela de tecidos moles, observando a mesma lesão. C) Imagem de TC do estudo pós-contraste na janela de pulmão com visualização do nódulo. D) Imagem de TC do estudo pós-contraste na janela de tecidos moles onde se constata o nódulo na mesma região.

Dias (2012) também observou um caso em que a imagem radiográfica pulmonar não apresentou indícios da presença de nodulações e o exame de imagem tomográfico indicou a presença de nódulo em parênquima pulmonar (Figura 3). 
Figura 3. Radiografia torácica e imagem de TC do tórax de um cão
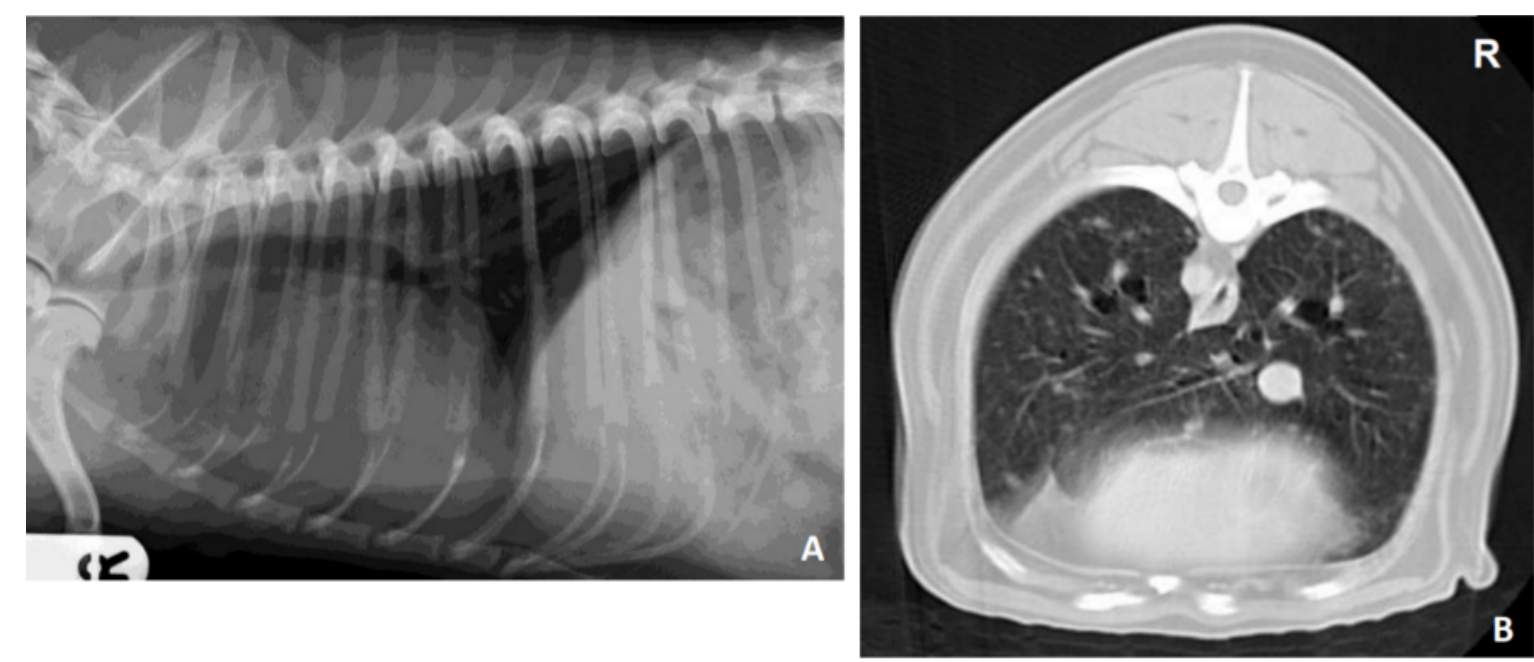

TFonte: DIAS, 2012.

A) Imagem de radiografia torácica indicando ausência de nodulação pulmonar. B) Imagem de tomografia computadorizada indicando a presença de nódulo em parênquima pulmonar.

Dias (2012) destacou que nos casos em que o tamanho da massa pulmonar era maior, com cerca de $60 \mathrm{~mm}$, a radiografia torácica permitiu a visualização da lesão, como mostra a Figura 4. Entretanto, quando realizado o exame de $\mathrm{TC}$, o mesmo indicou a presença de outra massa, também com grandes dimensões $(53,4 \times 37,4 \mathrm{~mm})$ e outras quatro pequenas nodulações $(5,4 \mathrm{~mm}, 3,9 \mathrm{~mm}, 2,8 \mathrm{~mm}$ e $2 \mathrm{~mm})$, como mostra a Figura 5.

Figura 4. Radiografia torácica de cão em posição lateral e ventro-dorsal
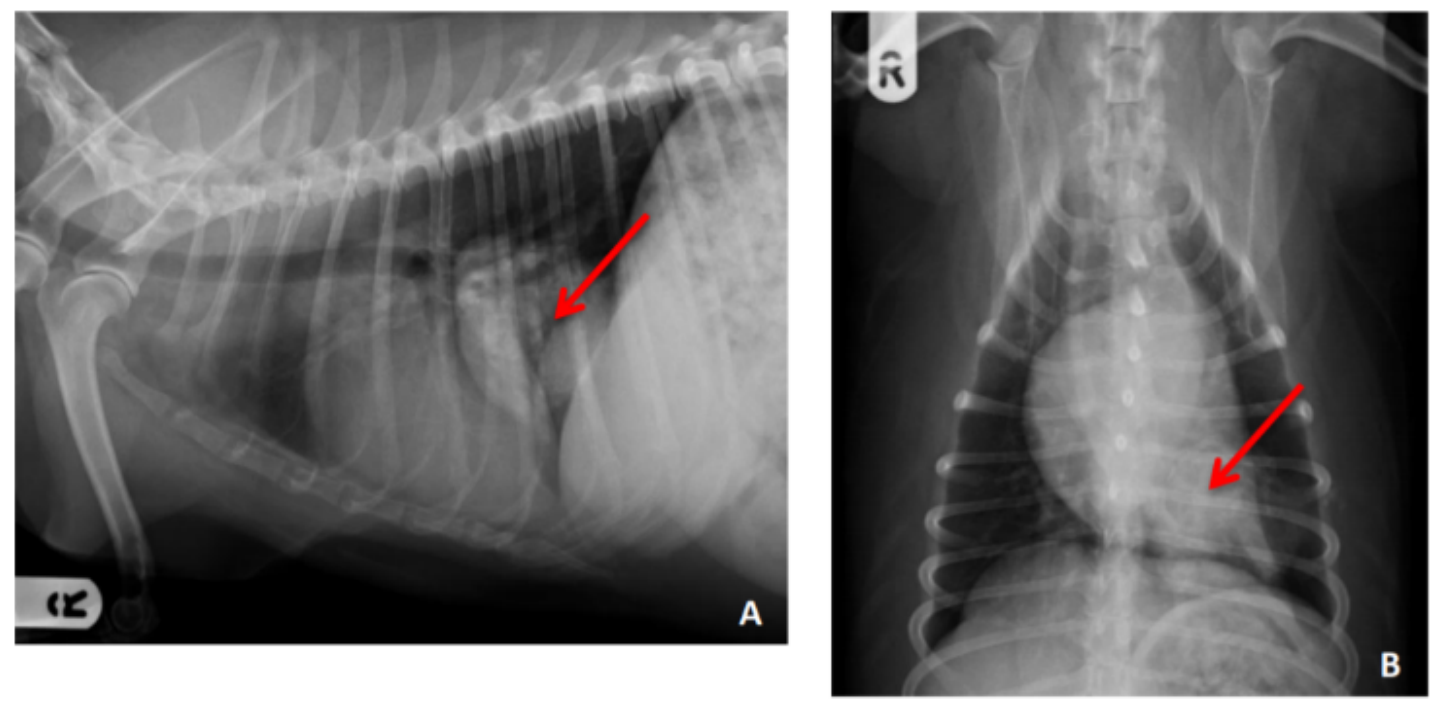

T Fonte: DIAS, 2012.

A) Imagem de radiografia torácica, na posição latero-lateral direita. B) Imagem de radiografia torácica na posição ventro-dorsal. Em ambas as imagens é possível visualizar a presença de uma grande nodulação, medindo cerca de aproximadamente $60 \mathrm{~mm}$ (seta vermelha). 
Figura 5. Imagem de tomografia computadorizada do canino referido na Figura 4, indicando a presença de outras massas pulmonares
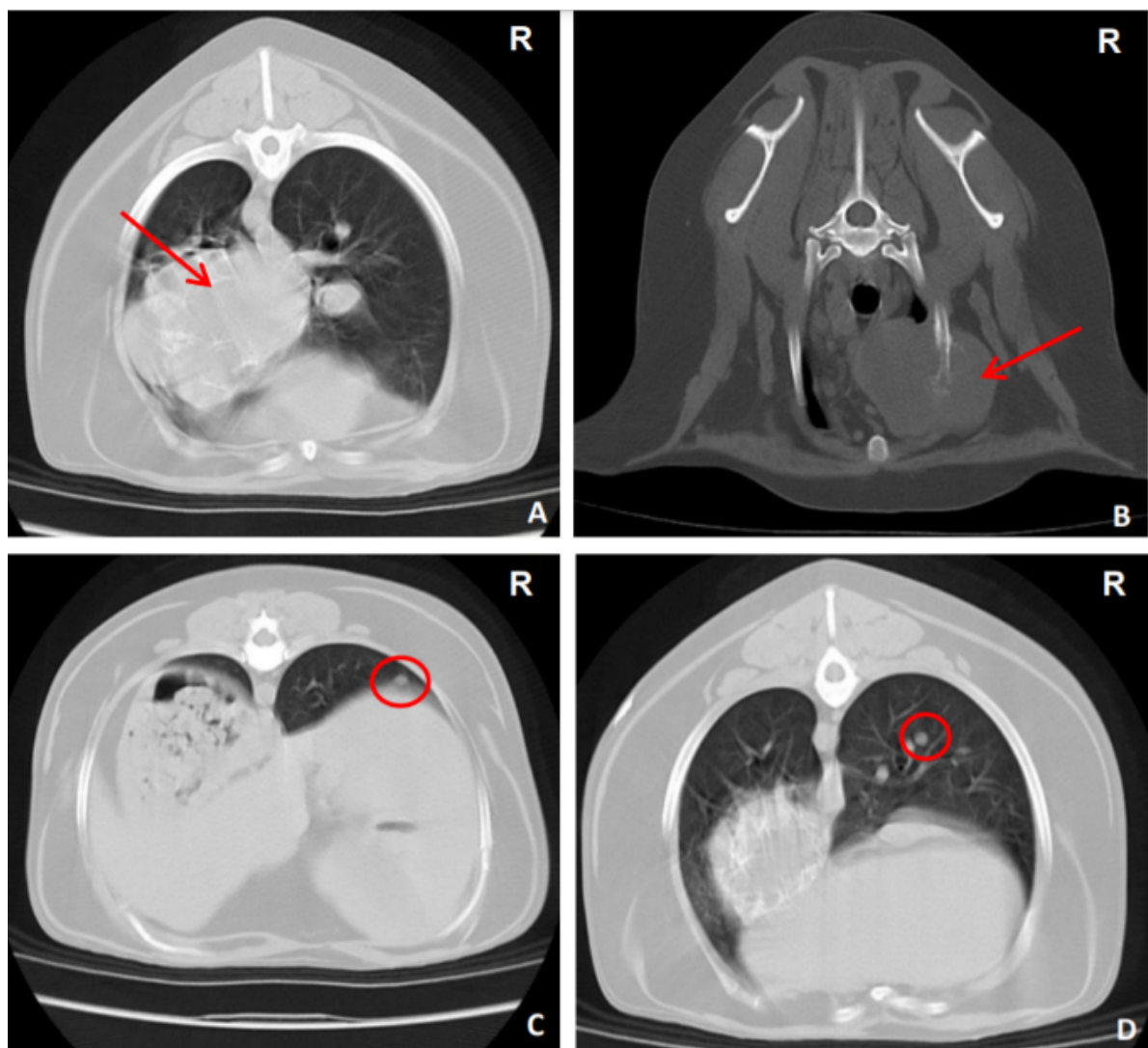

TFonte: DIAS, 2012

A) Imagem de TC na janela de pulmão, onde se observa uma massa localizada na porção cranial do lobo caudal esquerdo com dimensões aproximadas de 76,3 mm x 54,3 mm (seta vermelha). B) Imagem de TC na janela de tecidos moles onde se identifica uma massa, no lobo cranial direito, com dimensões aproximadas de 53,4 mm x 37,4 mm (seta vermelha).

C) Imagem de TC na janela de pulmão, onde se visualiza um pequeno nódulo na periferia do lobo pulmonar caudal direito (círculo vermelho). D) Imagem de TC na janela de pulmão, onde se observa um pequeno nódulo no lobo pulmonar médio direito (círculo vermelho).

\section{Planejamento terapêutico}

Nos últimos 20 anos, os tratamentos do câncer e as suas respectivas especializações têm crescido de forma considerável (MOREIRA et al., 2018). A escolha do protocolo terapêutico depende de uma série de fatores: custos, estado do animal, doenças concomitantes e envolvimento do proprietário. Os tratamentos possíveis incluem: cirurgia, radioterapia, quimioterapia e terapia fotodinâmica. Deve-se ficar atento aos animais idosos, pois nos casos em que for constatada a debilidade fisiológica, os protocolos conservativos são os mais indicados (HOSKINS, 2008). Terapêuticas cirúrgicas e radioterápicas são indicadas para tumores localmente invasivos e com baixa capacidade de metástase. Já a quimioterapia não visa a erradicação tumoral, atuando mais como um processo paliativo (NELSON; COUTO, 2001).

A realização do estadiamento do tumor baseia-se no princípio de que as neoplasias com uma mesma classificação e extensão apresentam uma resposta terapêutica e prognósticos semelhantes. Assim a escolha da terapia deve considerar o grau de acometimento do órgão de origem ou daqueles que já foram atingidos por metástases (BATSCHINSKI; TEDARDI apud DALECK; DE NARDI, 2017).

A excisão cirúrgica é considerada a terapia de primeira escolha. Contudo, em casos de carcinoma inflamatório e em pacientes que já apresentam processos metastáticos, a cirurgia não é recomendada. A 
técnica cirúrgica de escolha deve considerar o tamanho, a consistência e a localização do tumor (LANA et al., 2007). Os linfonodos sentinelas devem ser retirados no processo de mastectomia pois a sua avaliação é fundamental para a realização do estadiamento do tumor (CABRAL; VOLKWEIS, 2017). Complicações como sangramento, cosmética desagradável ou anormalidades funcionais podem ocorrer quando é adotada a remoção cirúrgica (NELSON; COUTO, 2001). 0 exame de tomografia computadorizada permite a delimitação do tumor e orienta o planejamento das margens cirúrgicas (LORIGADOS et al., 2013).

Quando o tratamento escolhido é a radioterapia, os profissionais devem utilizar exames de imagem para observar o tumor, as suas estruturas adjacentes, e, assim, determinar a sua localização exata, necessária para que o processo terapêutico seja eficiente. Esse conhecimento exato permite a utilização de uma dose alta, sem causar danos ao tecido adjacente. As imagens obtidas permitem a definição da área de tratamento, da dose e do período de exposição, sempre considerando a sensibilidade do tumor e das estruturas adjacentes (FONSECA, 2009). No caso da radioterapia, a TC deve ser realizada na mesma posição de tratamento para permitir a visualização e planejamento com melhor definição das áreas a serem tratadas. De fato, as imagens possibilitam a determinação do número de feixes, o ângulo de incidência e a quantidade de energia a ser aplicada (CARVALHO et al., 2009; PELLEJERO et al., 2009). As complicações dessa terapêutica incluem alopecia e/ou descamação permanente dos locais irradiados, necrose tecidual ou ainda a formação de fístulas ou estenose (NELSON; COUTO, 2001).

Silva (2018) utilizou a tomografia computadorizada para o planejamento da radioterapia, na região pélvica de uma leoa, contudo a técnica também pode ser aplicada em pequenos animais (Figura 6).

Figura 6. Planejamento dos campos de incidência e angulações dos raios radioterápicos aplicados em tomografia de pelve em uma leoa diagnosticada com leiomiossarcoma em região vulvar

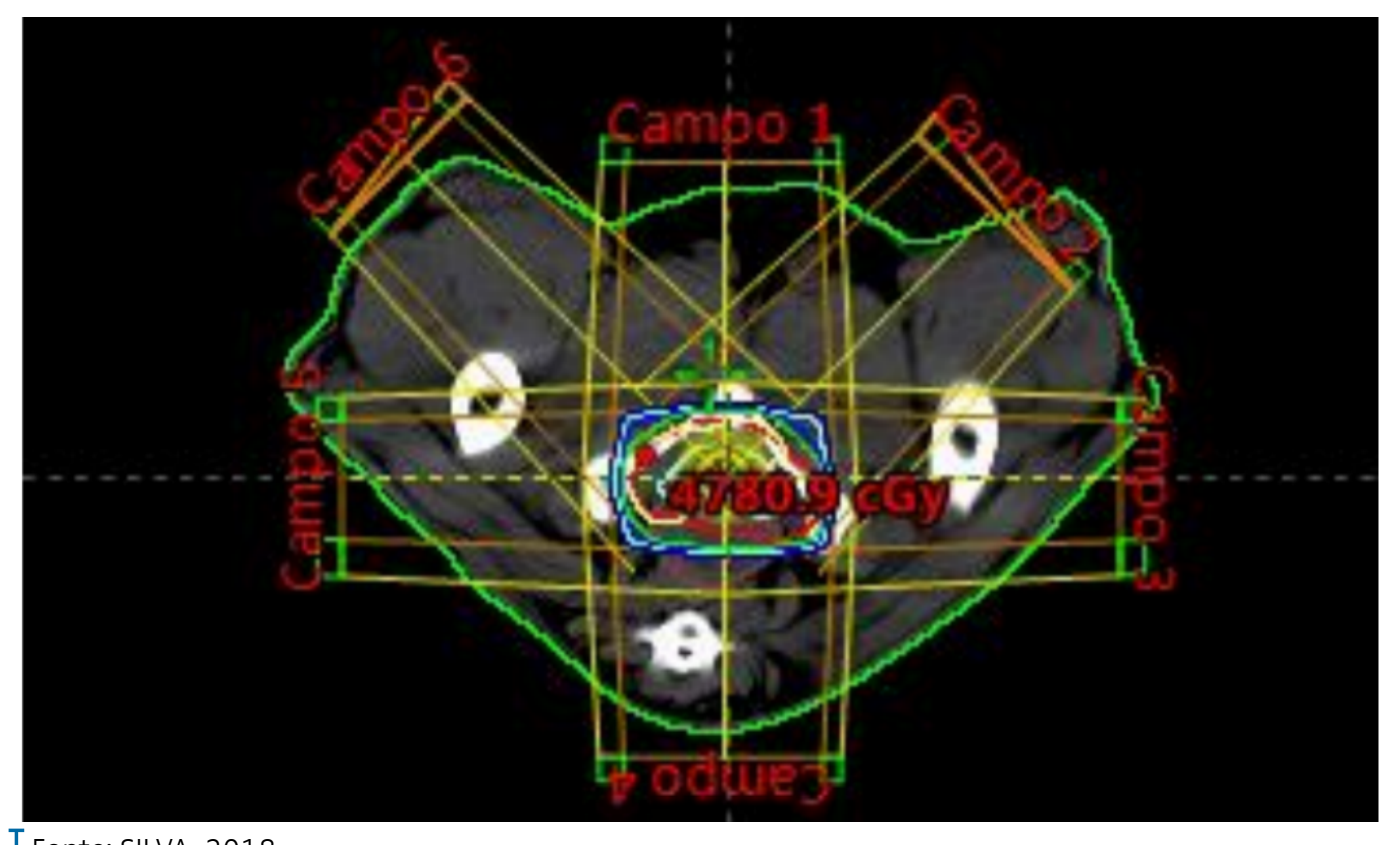

TFonte: SILVA, 2018.

Em tumores diagnosticados como malignos, a terapêutica quimioterápica pode ser realizada de forma adjuvante a procedimentos cirúrgicos, para diminuir a ocorrência de processos metastáticos (CIRILLO, 2008). Contudo é importante ficar atento às complicações e efeitos adversos causados pelos quimioterápicos, que incluem alterações gastrointestinais, hematológicas, dermatológicas, reações de hipersensibilidade e cardio, uro, hepato e/ou neurotoxicidade (NELSON; COUTO, 2001).

A partir das imagens obtidas, a tomografia pode gerar uma representação 3D do volume do tumor, que vai ser útil para o planejamento do tratamento do paciente (CARVALHO et al., 2009; PELLEJERO et al., 2009). 


\section{Avaliação da resposta à terapêutica aplicada}

Além do estadiamento, do auxílio na escolha de um protocolo de tratamento e planejamento terapêutico, a tomografia computadorizada também pode ser utilizada durante e após a realização da terapia para análise da resposta tumoral frente ao protocolo adotado, o que é importante para orientar os profissionais quanto à decisão de manter ou alterar os métodos escolhidos para combater a neoplasia.

A TC permite o acompanhamento pós-cirúrgico para análise de possível desenvolvimento de metástase ou ainda recidiva tumoral no mesmo local de origem, avaliando assim a necessidade de uma nova abordagem cirúrgica ou a utilização de outro método terapêutico adjacente como a quimioterapia ou a radioterapia. Para análise da eficácia terapêutica quimioterápica é utilizado o método RECIST (Response Evaluation Criteria in Solid Tumors) e a mensuração volumétrica que apresentam uma boa classificação da resposta terapêutica, fornecendo um parâmetro da eficácia do tratamento instituído. (LORIGADOS et al., 2013).

No RECIST, as imagens tomográficas permitem a mensuração unidimensional da lesão no seu maior diâmetro. Com isso, o tumor é classificado em quatro categorias: a) se o processo tumoral desapareceu por completo, remissão completa (RC); b) se houve diminuição mínima de $30 \%$, remissão parcial (RP); c) se a neoplasia cresceu no mínimo $20 \%$, ou se houve a ocorrência de novos processos tumorais, doença progressiva (DP); d) se não se enquadra em RP ou DP, doença estável (DE) (SUZUKI et al., 2008; MAROTTI, 2009; STACCHIOTTI et al., 2009; D'IPPOLITO et al., 2011).

\section{Considerações finais}

A tomografia computadorizada tem grande aplicabilidade técnica para a rotina clínica oncológica veterinária, permitindo a detecção de processos metastáticos iniciais, principalmente pulmonares, quando comparada à técnica de radiografia comum. Além disso, orienta o planejamento e a avaliação da eficácia da terapia adotada, pois permite uma melhor visualização tumoral e das estruturas adjacentes. Contudo, em função do custo e da acessibilidade nas clínicas veterinárias, os exames radiográficos ainda são o principal procedimento de imagem utilizado para a busca de metástases.\&

\section{Referências}

BATSCHINSKI, K.; TEDARDI, M. V. Estadiamento clínico das neoplasias. In: DALECK, C. R.; DE NARDI, A. B. Oncologia em cães e gatos. 2. ed. Rio de Janeiro: Roca, 2017. p. 55-61.

BRELINGER, A. F. et al. Imagem funcional em oncologia. In: FIGUEIREDO, E.; MONTEIRO, M.; FERREIRA, A. Tratado de oncologia. Rio de Janeiro: Revinter, 2015. p. 295-299.

CABRAL, L. A.; VOLKWEIS, F. S. Terapêutica clínico-cirúrgica de neoplasias mamárias em cadelas.

Revista Científica de Medicina Veterinária, Brasília v. 4, n. 2, p. 16-30, 2017. Disponível em: http:// revista.faciplac.edu.br/index.php/Revet/article/view/317. Acesso em: 20 jun. 2020.

CANOLA, J. C. et al. Radiografia convencional, ultrassonografia, tomografia e ressonância magnética. In: DALECK, C. R.; DE NARDI, A. B. Oncologia em cães e gatos. 2. ed. Rio de Janeiro: Roca, 2017. p. 78112.

CARVALHO, A. C. P. História da tomografia computadorizada. Revista da Imagem, [s.I.], v. 29, n. 2, p. 61-67, 2007. Disponível em: http://imaginologia.com.br/dow/upload\%20historia/Historia-daTomografia-Computadorizada.pdf. Acesso em: 20 jun 2020. 
CARVALHO, H. A. et al. Comparação entre os volumes pulmonares irradiados com técnica bidimensional e tridimensional conformada na radioterapia de pacientes com tumores de pulmão localmente avançados. Radiologia Brasileira, São Paulo, v. 42, n. 5, p. 303-308, 2009. DOI: https:// doi.org/10.1590/S0100-39842009000500009. Disponível em: https://www.scielo.br/pdf/rb/ v42n5/a09v42n5.pdf. Acesso em: 19 set. 2020.

CASSALI, G. D. et al. Consensus for the diagnosis, prognosis and treatment of canine mammary tumors - 2013. Brazilian Journal of Veterinary Pathology, [s.I.], v. 7, n. 2, p. 38-69, 2014. Disponível em: https://bjvp.org.br/bjvp-archive/2015/07/vol-7-n-2-july-2014/. Acesso em: 25 ago. 2020.

CIRILLO, J. V. Tratamento quimioterápico das neoplasias mamárias em cadelas e gatas. Revista do Instituto de Ciências da Saúde, [s.l.], v. 26, n. 3, p. 325-327, 2008. Disponível em: https://www.unip. br/presencial/comunicacao/publicacoes/ics/edicoes/2008/03_jul_set/V26_N3_2008_p325-327. pdf. Acesso em: 19 ago. 2020.

DE NARDI, A. B. et al. Neoplasias mamárias. In: DALECK, C. R.; DE NARDI, A. B. Oncologia em cães e gatos. 2. ed. Rio de Janeiro: Roca, 2016. p. 498-516.

DIAS, J. N. R. Diagnóstico imaginológico de metastização pulmonar: radiografia versus tomografia computorizada. 2012. 113 f. Dissertação (Mestrado Integrado em Medicina Veterinária) - Faculdade de Medicina Veterinária, Universidade Técnica de Lisboa, Lisboa, 2012.

D'IPPOLITO, G. et al. CT and MRI in monitoring response: state-of-the-art and future developments. The Quarterly Journal of Nuclear Medicine and Molecular Imaging, [s.I.], v. 55, n. 6, p. 603-619, 2011. Disponível em: https://pubmed.ncbi.nlm.nih.gov/22231581/. Acesso em: 24 jul. 2020.

FONSECA PINTO, A. C. B. C. et al. Tomografia computadorizada do tórax de cadelas portadoras de neoplasias malignas: II-Avaliação dos campos pulmonares. Brazilian Journal of Veterinary Research and Animal Science, [s.l.], v. 44, n. 3, p. 174-182, 2007. DOl: https://doi.org/10.11606/issn.1678-4456.bjvras.2007.26636. Disponível em: http://www.periodicos.usp.br/bjvras/article/view/26636/28419. Acesso em: 22 jul. 2020.

FONSECA, T. C. F. Desenvolvimento de um sistema computacional para o planejamento radioterápico com a técnica IMRT aplicado ao código MCNP com interface gráfica 3D para modelos de voxel. 2009. 141 f. Dissertação (Mestrado em Ciências e Técnicas Nucleares) Universidade Federal de Minas Gerais, Belo Horizonte, 2009. Disponível em: https://www.osti.gov/ etdeweb/servlets/purl/21501415. Acesso em: 22 jun. 2020.

FOSSUM, T. W. Cirurgia de pequenos animais. 4. ed. [s. I.]: Elsevier, 2014.

FREHSE, M. S. et al. Epidemiological and histological aspects of canine mammary tumors diagnosed at the Veterinary Teaching Hospital/UEL. Brazilian Journal of Veterinary Pathology, [s.I.], v. 7, n. 2, p. 118-122, 2014. Disponível em: http://bjvp.org.br/wp-content/uploads/2015/07/DOWLOAD-FULLARTICLE-9-20881_2014 7 31_18 51.pdf. Acesso em: 22 jul. 2020.

HEDLUND, C. Cirurgia dos sistemas reprodutivos e genital. In: FOSSUM, T. W. Cirurgia de pequenos animais. Tradução de Ângela Manetti et al. 4. ed. Rio de Janeiro: Mosby Elsevier, 2014. p. 809-815.

HELLMEN, E. et al. Prognostic factors in canine mammary gland tumors: a multivariate study of 202 consecutive cases. Veterinary Pathology, [s.I.], v. 30, n. 1, p. 20-27, Jan. 1993. DOI: https:// doi.org/10.1177/030098589303000103. Disponível em: https://journals.sagepub.com/doi/ pdf/10.1177/030098589303000103. Acesso em: 15 jun. 2020.

HOSKINS, J. D. Geriatria e gerontologia do cão e gato. 2. ed. São Paulo: Roca, 2008. 448 p.

JANSSENS, T. et al. Inductively coupled plasma mass-spectrometric determination of platinum in excretion products of client-owned pet dogs. Veterinary and Comparative Oncology, [s.l.], v. 13, n. 2, p. 124-132, 2015. DOl: https://doi.org/10.1111/vco.12025. Disponivel em: https://pubmed. ncbi.nlm.nih.gov/23714139/. Acesso em: 24 jul. 2020. 
LAMB, C. R. O pulmão de cães e gatos. In: THRALL, D. E. Diagnóstico de radiologia veterinária. 5. ed. Rio de Janeiro: Elsevier, 2010. p. 591-608.

LANA, S. E.; RUTTEMAN, G. R.; WITHROW, S. J. Tumors of the mammary gland. In: WITHROW., S.; VAIL, D. Withrow \& MacEwen's small animal clinical oncology. 4. ed. St. Louis: Saunders, 2007. p. 619-636. DOI: https://doi.org/10.1016/B978-072160558-6.50029-0.

LEANDRO, R. M.; SÁ, L. R. M. Tumor estromal gastrointestinal em cães: estudo clínicoanatomopatológico. Arquivo Brasileiro de Medicina Veterinária e Zootecnia, Belo Horizonte, v. 68, n. 4, p. 938-944, 2016. DOI: https://doi.org/10.1590/1678-4162-8767. Disponível em: http://www. scielo.br/scielo.php?script=sci_arttext\&pid=S0102-09352016000400938\&lng=en\&nrm=iso. Acesso em: 19 ago. 2020.

LORIGADOS, C. A. B. et al. Tomografia computadorizada de mastocitomas em cães: avaliação pré e pós-tratamento quimioterápico. Pesquisa Veterinária Brasileira, Goiânia, v. 33, n. 11, p. 1349-1356, nov. 2013. DOl: https://doi.org/10.1590/S0100-736X2013001100011. Disponível em: https:// www.scielo.br/pdf/pvb/v33n11/v33n11a11.pdf. Acesso em: 15 jun. 2020.

MAROTTI, M. Por que revisar os critérios de resposta em tumores sólidos? Revista da Associação Médica Brasileira, São Paulo, v. 55, n. 4, p. 369-371, 2009. DOl: https://doi.org/10.1590/ S0104-42302009000400005. Disponivel em: http://www.scielo.br/scielo.php?script=sci arttext\&pid=S0104-42302009000400005\&lng=en\&nrm=iso. Acesso em: 19 set. 2020.

MEDEIROS, V. B. Câncer da mama na cadela. Journal of Surgical and Clinical Research, [s.I.], v. 8, n. 1, p. 118-129, 2017. DOI: https://doi.org/10.20398/jscr.v8i1.13039. Disponível em: https://periodicos. ufrn.br/jscr/article/view/13039/8925. Acesso em: 22 jul. 2020.

MOREIRA, L. et al. A geriatria canina e o manejo das doenças neoplásicas: revisão. Pubvet, Maringá, v. 12, n. 4, p. 1-7, abr. 2018. DOl: https://doi.org/10.1590/1678-4162-8767. Disponível em: https:// www.pubvet.com.br/uploads/b0442ade51408d070211021a18708cfe.pdf. Acesso em: 22 jul. 2020.

MORIMOTO, C. Y. et al. Evaluation of the global DNA methylation in canine mast cell tumour samples by immunostaining of 5 - methyl cytosine. Veterinary and Comparative Oncology, [s.l.], v. 15, n. 3, p. 1014-1018, 2017. DOl: https://doi.org/10.1111/vco.12241. Disponível em: https://pubmed.ncbi. nlm.nih.gov/27140659/. Acesso em: 22 jul. 2020.

NELSON, R. W.; COUTO, C. G. Princípios de tratamento do câncer. In: NELSON, R. W.; COUTO, C. G. Medicina interna de pequenos animais. 2.ed. Rio de Janeiro: Guanabara Koogan, 2001. p. 864-866.

OLIVEIRA FILHO, J. C. et al. Estudo retrospectivo de 1.647 tumores mamários em cães. Pesquisa Veterinária Brasileira, Rio de Janeiro, v. 30, n. 2, p. 177-185, fev. 2010. DOl: https://doi. org/10.1590/S0100-736X2010000200014. Disponível em: https://www.scielo.br/pdf/pvb/v30n2/ v30n2a14.pdf. Acesso em: 15 jun. 2020.

OTONI, C. C. et al. Survey radiography and computerized tomography imaging of the thorax in female dogs with mammary tumors. Acta Veterinaria Scandinavica, [s.I.], v. 52, n. 20, p. 1-10, Mar. 2010. DOI: https://doi.org/10.1186/1751-0147-52-20. Disponível em: https://actavetscand. biomedcentral.com/articles/10.1186/1751-0147-52-20. Acesso em: 20 jun. 2020.

PELLEJERO, S.; LOZARES, S.; MAÑERU, F. Descripción de equipos de última generación en radioterapia externa. Anales del Sistema Sanitario de Navarra, Pamplona, v. 32, p. 13-20, 2009. Supl. 2. DOI: https://doi.org/10.23938/ASSN.0181. Disponivel em: http://scielo.isciii.es/pdf/asisna/v32s2/ original2.pdf. Acesso em: 19 set. 2020.

PINHEIRO, D. J. P. C.; ELIAS, S.; NAZÁRIO, A. C. P. Linfonodos axilares em pacientes com câncer de mama: avaliação ultrassonográfica. Radiologia Brasileira, [s.I.], v. 47, n. 4, p. 240-244, jul./ago. 2014. DOI: https://doi.org/10.1590/0100-3984.2013.1689. Disponível em: https://www.scielo.br/pdf/rb/ 
v47n4/0100-3984-rb-47-04-0240.pdf. Acesso em: 24 jul. 2020.

QUEIROGA, F.; LOPES, C. Tumores mamários caninos, pesquisa de novos factores de prognóstico.

Revista Portuguesa de Ciências Veterinárias, [s.I.], v. 97, n. 543, p. 119-127, 2002. Disponível em: http://www.fmv.ulisboa.pt/spcv/PDF/pdf9 2002/13 RPCV543.pdf. Acesso em: 15 jun. 2020.

SCHWARZ, L. A.; TIDWELL, A. S. Alternative imaging of the lung. Clinical Techniques in Small Animal Practice, [s.I.], v. 14, n. 4, p. 187-206, Nov. 1999. DOl: https://doi.org/10.1016/S10962867(99)80011-5. Disponível em: https://www.sciencedirect.com/science/article/abs/pii/ S1096286799800115. Acesso em: 25 ago. 2020.

SERKOVA, N. J.; GARG, K.; BRADSHAW-PIERCE, E. L. Oncologic imaging end-points for the assessment of therapy response. Recent Pat Anticancer Drug Discov, [s.I.], v. 4, n. 1, p. 36-53, Jan. 2009. DOI: https://doi.org/10.2174/157489209787002434.

\section{SILVA, D. A. Planejamento computacional tridimensional para radioterapia em região pélvica} de animais selvagens. 2018. 95 f. Dissertação (Mestrado) - Faculdade de Medicina Veterinária e Zootecnia, Universidade Estadual Paulista, Botucatu, 2018.

SILVA, M. P. N. Síndrome da anorexia-caquexia em portadores de câncer. Revista Brasileira de Cancerologia, [s.I.], v. 52, n. 1, p. 59-77, 2006. DOl: https://doi.org/10.32635/2176-9745. RBC.2006v52n1.1910.

SORENMO, K. U. et al. Development, anatomy, histology, lymphatic drainage, clinical features, and cell differentiation markers of canine mammary gland neoplasms. Veterinary Pathology, [s.l.], v. 48, n. 1, p. 85-97, 2011. DOI: https://doi.org/10.1177/0300985810389480. Disponível em: http://citeseerx. ist.psu.edu/viewdoc/download?doi=10.1.1.989.8639\&rep=rep1\&type=pdf. Acesso em: 15 jun. 2020.

STACCHIOTTI, S. High-grade soft-tissue sarcomas: tumor response assessment: pilot study to assess the correlation between radiology and pathologic response by using RECIST and Choi criteria. Radiology, [s.I.], v. 251, n. 2, p. 447-456, May 2009. DOI: https://doi.org/10.1148/ radiol.2512081403. Disponível em: https://pubs.rsna.org/doi/pdf/10.1148/radiol.2512081403. Acesso em: 24 jul. 2020.

SUZUKI, C. et al. Radiologic measurements of tumor response to treatment: practical approaches and limitations. RadioGraphics, [s.l.], v. 28, n. 2, p. 329-344, Mar./Apr. 2008. DOI: https://doi. org/10.1148/rg.282075068. Disponível em: https://pubs.rsna.org/doi/pdf/10.1148/rg.282075068. Acesso em: 22 jun. 2020.

WITHROW, S. J.; VAIL, D. M.; PAGE, R. L. Imaging in oncology. In: WITHROW, S.; VAIL, D. Withrow and MacEwen's small animal clinical oncology. 5. ed. Saint Louis: Saunders, 2013. p. 98-104. 